University of Nebraska - Lincoln

DigitalCommons@University of Nebraska - Lincoln

Publications, Agencies and Staff of the U.S.

Department of Commerce

U.S. Department of Commerce

2009

Recent changes in benthic macroinvertebrate populations in Lake

Huron and impact on the diet of lake whitefish (coregonus

clupeaformis)

Thomas F. Nalepa

NOAA, thomas.nalepa@noaa.gov

Steven A. Pothoven

NOAA

David L. Fanslow

NOAA

Follow this and additional works at: https://digitalcommons.unl.edu/usdeptcommercepub

Part of the Environmental Sciences Commons

Nalepa, Thomas F.; Pothoven, Steven A.; and Fanslow, David L., "Recent changes in benthic macroinvertebrate populations in Lake Huron and impact on the diet of lake whitefish (coregonus clupeaformis)" (2009). Publications, Agencies and Staff of the U.S. Department of Commerce. 367. https://digitalcommons.unl.edu/usdeptcommercepub/367

This Article is brought to you for free and open access by the U.S. Department of Commerce at DigitalCommons@University of Nebraska - Lincoln. It has been accepted for inclusion in Publications, Agencies and Staff of the U.S. Department of Commerce by an authorized administrator of DigitalCommons@University of Nebraska - Lincoln. 


\title{
Recent changes in benthic macroinvertebrate populations in Lake Huron and impact on the diet of lake whitefish
}

\author{
(coregonus clupeaformis)
}

\author{
Thomas F. Nalepa, ${ }^{*}$ Steven A. Pothoven, and David L. Fanslow \\ Great Lakes Environmental Research Laboratory, NOAA, 4840 S. State Rd., Ann Arbor, MI 48108 \\ *Corresponding author: Thomas.nalepa@noaa.gov
}

\begin{abstract}
Surveys of the benthic macroinvertebrate community were conducted in the main basin of Lake Huron in 2000 and 2003, and corresponding studies of lake whitefish diets were conducted in 2002-2004. Populations of three major benthic taxa, Diporeia spp., Sphaeriidae, and Chironomidae, declined dramatically between 2000 and 2003, with densities declining 57\%, 74\%, and 75\% over this 3-year period. By 2003, Diporeia, an important food source for lake whitefish, was gone or rare at depths $<50 \mathrm{~m}$ except in the far northeastern portion of the lake. In contrast, densities of the Dreissena bugensis (quagga mussel) increased between 2000 and 2003, particularly at the 31-50 m depth interval, while densities of the zebra mussel Dreissena polymorpha remained stable. As expected, the diet of lake whitefish varied with fish size. Age-0 lake whitefish fed mainly zooplankton, most of which were Daphnia (98\%). Medium lake whitefish (<350 mm excluding age-0 fish) fed mainly on zooplankton, Chironomidae, and Dreissena bugensis, and large lake whitefish (350 to $688 \mathrm{~mm}$ ) fed mainly on $\mathrm{D}$. bugensis and Gastropoda. The diet of medium and large lake whitefish reflected the changing nature of the benthic community; that is, Diporeia was rarely found in the diet while D. bugensis played a prominent role. Since Diporeia has a much higher energy content than D. bugensis, contrasting density trends in the two organisms will have long term consequences to the relative health of lake whitefish populations in the lake.
\end{abstract}

Keywords: benthos, Diporeia spp., Dreissena, macroinvertebrate-fish interaction

\section{Introduction}

Benthic macroinvertebrate communities in the Great Lakes are currently undergoing broad changes in both nearshore and offshore areas. While at least some changes may be a result of phosphorus control measures initiated in the 1970s, evidence suggests that by far the greatest changes can be attributed to the introduction and spread of dreissenids (zebra mussel Dreissena polymorpha and quagga

This article is not subject to US copyright law. mussel Dreissena bugensis) beginning in the late 1980s (Nalepa et al., 1998, 2003). Through their high abundances and capacity for filtering seston, dreissenids impact other benthic organisms by 1) competing for organic food material settling to the bottom from the water column, 2) creating large shell beds that change the physical complexity of the substrate, and 3) depositing organic wastes on the bottom that alter the biochemical nature of the benthic environment (Howell et al., 1996; Gonzalez and Downing, 1999; Bially and MacIsaac, 2000; Haynes et al., 2005). Responses of benthic taxa to these dreissenid-induced changes are complex and 
varied, and depend on the life habits of the particular organism. For example, populations of the cold-water amphipod Diporeia have declined dramatically since the introduction of Dreissena, and large areas in all the lakes except Lake Superior are now completely devoid of this organism (Nalepa et al., 2006). Despite a clear temporal pattern, however, the exact mechanism for the negative response of Diporeia to Dreissena remains unknown. In contrast, the warm-water amphipod Gammarus has increased, apparently as a result of its ability to utilize dreissenid biodeposits as a food source (Gonzalez and Downing, 1999; Nalepa et al., 2003).

Observed changes in the benthic community have broad implications to fish species that rely heavily on this community as a source of food. Of special interest is the lake whitefish (Coregonus clupeaformis), which is an important commercial species in Lake Huron and in the other Great Lakes (Mohr and Nalepa, 2005). Adult lake whitefish are benthivores that feed primarily on Diporeia (Ihssen et al., 1981; Christie et al., 1987), and the recent loss of this amphipod has been implicated in the decline of whitefish growth, condition, and abundance in both Lakes Michigan and Ontario (Pothoven et al., 2001, Owens and Dittman, 2003). While whitefish growth and condition have also declined in Lake Huron (Mohr and Ebener, 2005), collaborative studies on benthic prey availability and associated fish diets have not been conducted. In this paper, we present a synopsis of several studies in Lake Huron between 2000 and 2004 that examine the status and recent changes in the benthic community, and also examine how these changes have affected the diet of lake whitefish. More detailed accounts of these studies have been published previously (Pothoven and Nalepa, 2006; Nalepa et al., 2007a).

\section{Methods}

Samples for benthic community analysis were collected at 65 sites in July/August 2000 and at 85 sites in July/August 2003 (Fig. 1). All sites sampled in 2000 were re-sampled in 2003 along with 20 additional sites within specific areas where whitefish were collected. Triplicate samples were taken at each site with a Ponar grab (area $=0.047$ $\mathrm{m}^{2}$ ) and then washed into an elutriation device fitted with a nitex sleeve having $0.5-\mathrm{mm}$ openings. Retained material was immediately preserved in $5 \%$ buffered formalin containing rose bengal stain.
In the laboratory, retained residue was placed in a white enamel pan, and organisms were picked, counted, and sorted into major taxonomic groups (Amphipoda, Oligochaeta, Chironomidae, Dreissena, Sphaeriidae, and other) under a low-power magnifier lamp $(1.5 \times)$. All organisms collected in 2000 were identified to the lowest practical taxonomic level. For oligochaetes, between 75 and 100 individuals in a replicate (proportionately split with a Folsom plankton splitter when numbers were high) were cleared in lacto-nophenol and mounted on slides before identification. Only oligochaetes with a prostomium were included in abundance estimates. In 2003, oligochaetes and chironomids were not identified beyond the group level. Since oligochaete fragments (without prostomium) can only be recognized during the process of species identification and not when counted and sorted, the total number of oligochaetes at each site in 2003 was corrected based on the mean proportion of fragments found at the same site in 2000 (see Nalepa et al., 1998). For the 20 sites sampled in 2003 and not in 2000, a mean proportion for all sites in the same depth interval was used as the oligochaete correction factor. The number of each species found in each replicate at all the sites sampled in the 2000 and 2003 surveys, along with site coordinates, are given in Nalepa et al., (2007b). For purposes of analysis, all sites were placed into four depth intervals (0$30 \mathrm{~m}, 31-50 \mathrm{~m}, 51-90,>90 \mathrm{~m})$, and differences between years were tested for each interval and each major taxonomic group using the Mann Whitney U-Test.

Lake whitefish Coregonus clupeaformis were collected periodically during May thru September 2002-2004. Sampling occurred between the Straits of Mackinac and Harbor Beach in U.S. waters and between Chief's Point and Grand Bend in Canadian waters. Lake whitefish were collected with overnight bottom gill net sets. Gill nets used in U. S. waters were $823 \mathrm{~m}$ long $\times 1.83 \mathrm{~m}$ deep with 9 panels of $5.1-15.2 \mathrm{~cm}$ stretch mesh in $1.27 \mathrm{~cm}$ increments. Gill nets used in Canadian waters were $400 \mathrm{~m}$ long $\times 1.83 \mathrm{~m}$ deep with $2 \times 25 \mathrm{~m}$ panels of 3.2 and 3.8 $\mathrm{cm}$ stretch mesh and $7 \times 50 \mathrm{~m}$ panels of 5.1-12.7 $\mathrm{cm}$ mesh in $1.27 \mathrm{~cm}$ increments. Gill net collections were part of assessment efforts by the Michigan Department of Natural Resources, United States Fish and Wildlife Service, and the Ontario Ministry of Natural Resources. Additional collections were made in U.S. waters at night using a 7.6-m semiballoon 4-seam Skate model bottom trawl (13-mm 


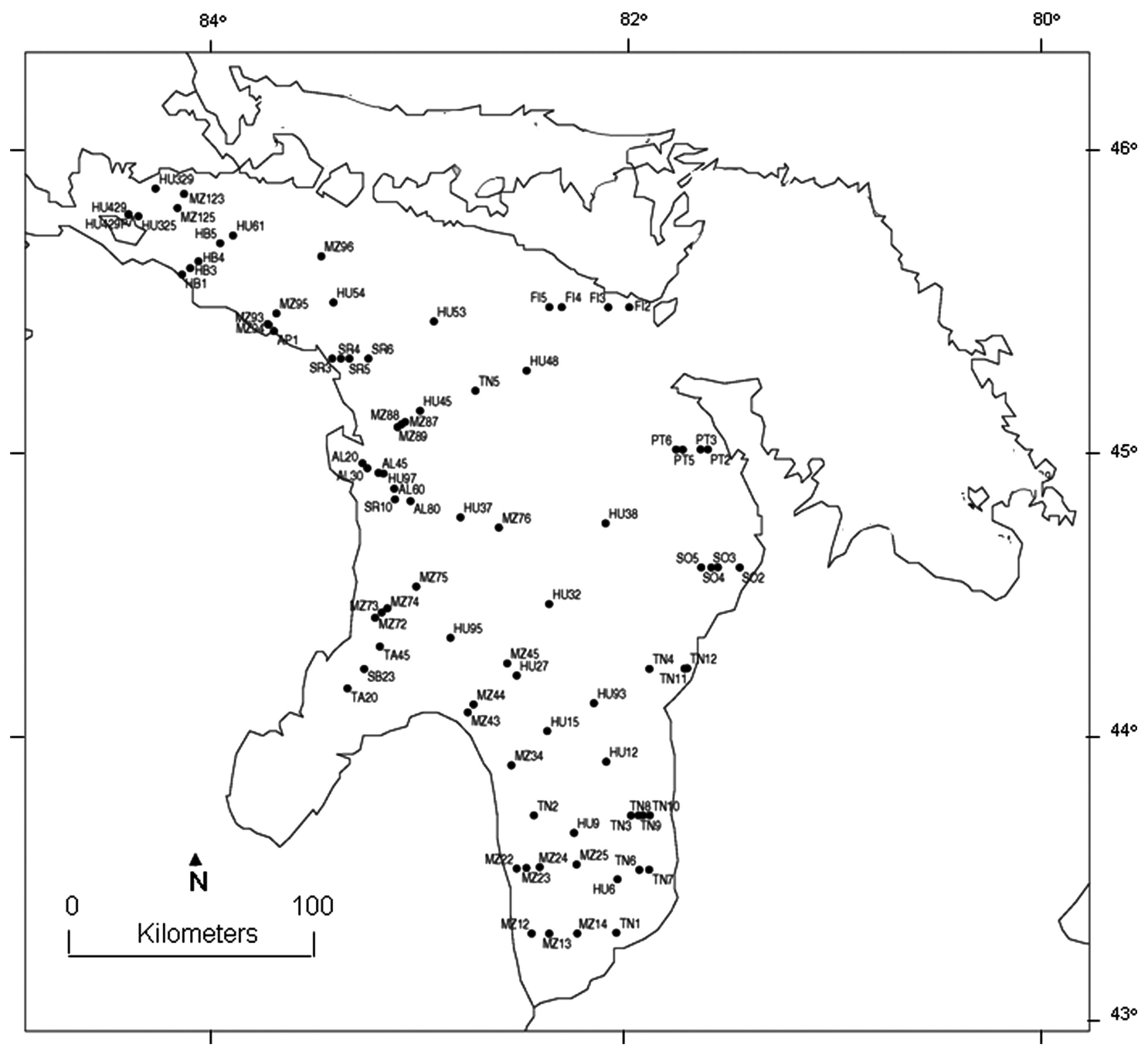

Figure 1. Sites sampled in the main basin of Lake Huron in $2003(\mathrm{n}=85)$. Twenty fewer sites were sampled in $2000(\mathrm{n}=65)$. Sites sampled in 2003 but not in 2000 are given in Nalepa et al. (2007b).

stretched-mesh cod-liner). All fish were collected in water depths of 11-61 m (average $31 \mathrm{~m})$.

All fish were weighed (nearest $\mathrm{g}$ ) and measured (total length $\pm 1 \mathrm{~mm}$ ) and stomachs (esophagus to pyloric caeca) were removed and frozen. A scale sample was taken from each fish for aging. In the laboratory, stomachs were dissected and prey items were separated, identified, counted, and weighed (nearest $0.1 \mathrm{mg}$ ) by prey group (wet weight). Measured weights of molluscs found in the stomachs included shells. Of the 1,188 stomachs examined, $23 \%$ were empty and not included in subsequent analyses. Diet analysis was done separately for age- 0 , medium $(\leq 350 \mathrm{~mm}$ excluding age-
$0)$, and large (350-688 mm) lake whitefish. Age-0 fish were only collected during July thru September. Age-0 fish ranged in length from $73-149 \mathrm{~mm}$ and were separated from older fish by aging scales and examining size frequency distributions. The size designation for medium and large fish was chosen because lake whitefish in the main basin of Lake Huron begin maturing around age-4 (Mohr and Ebener, 2005), and the average total length of age-4 fish in our study was about $350 \mathrm{~mm}$. Diet is reported as the percentage each prey item comprised of the total measured wet weight of all prey items summed across all fish for each respective size class. 


\section{Results}

\section{Changes in Benthic communities,} 2000-2003

Total density of the four major non-dreissenid taxonomic groups (Diporeia, Oligochaeta, Sphaeriidae, and Chironomidae) was lower in 2003 compared to 2000 . Mean $( \pm$ SE) total density was 2,923 $\pm 219 \cdot \mathrm{m}^{-2}$ in 2000 compared to $1,707 \pm 158 \cdot \mathrm{m}^{-2}$ in 2003. Densities of Diporeia, Sphaeriidae, and Chironomidae decreased $57 \%, 74 \%$, and $75 \%$ in the 3-year period, but no overall change was apparent in densities of Oligochaeta. Between-year density differences in Diporeia and Chironomidae were significant (Mann Whitney U-Test, $\mathrm{P}<0.05$ ) at the $31-50 \mathrm{~m}, 51-90 \mathrm{~m}$, and $>90 \mathrm{~m}$ depth intervals, while density differences in Sphaeriidae were significant only at the 31-50 m and 51-90 m intervals (Fig. 2). Between-year differences at the $<30$ $m$ interval were not significant $(P>0.05)$ for all three groups, likely a result of high variation between sites. Between 2000 and 2003, densities of Oligochaeta increased at the $<30 \mathrm{~m}$ and $31-50 \mathrm{~m}$ intervals, but decreased at the 51-90 and $>90 \mathrm{~m}$ intervals (Fig. 2). Only the difference at the $51-90 \mathrm{~m}$ interval was significant $(\mathrm{P}<0.05)$.

While both Sphaeriidae and Chironomidae declined uniformly across the whole lake within a given depth interval, the spatial pattern was somewhat different for Diporeia (see Fig.2; Nalepa et al., 2007a). In 2000, Diporeia was rare in the southern portion of the main basin, in outer Saginaw Bay, and at depths $<30 \mathrm{~m}$ along the western portion of the lake. By 2003, few or no Diporeia were found at sites $<50 \mathrm{~m}$ around the entire lake except for the northeast portion. Of sites sampled in both 2000 and 2003, the number of sites where Diporeia was not found increased from 6 to 12 over the 3 -year period.

In contrast to the other taxonomic groups, the dreissenid population expanded in 2003 compared to 2000 , mainly a result of the great increase in densities of D. bugensis (Fig. 2). The mean lakewide density of $D$. bugensis was $<1 \pm<1 \cdot \mathrm{m}^{-2}$ in 2000 , but increased to $560 \pm 253 \cdot \mathrm{m}^{-2}$ in 2003 . The greatest increase occurred at the $31-50 \mathrm{~m}$ interval where densities increased from $2 \cdot \mathrm{m}^{-2}$ to $1,469 \cdot \mathrm{m}^{-2}$. The difference between years was significant at this interval and at the 51-90 m interval $(\mathrm{P}<0.05)$. In contrast, densities of $D$. polymorpha were similar in 2000 and 2003; mean density was $61 \pm 53 \cdot \mathrm{m}^{-2}$ in 2000 and $68 \pm 48 \cdot \mathrm{m}^{-2}$ in 2003 , and yearly differ- ences were not significant $(\mathrm{P}>0.05)$ at any of the four depth intervals.

\section{Lake whitefish diet}

Age-0 lake whitefish ate mainly zooplankton (87\%) during the July-September period (Table 1). The zooplankton eaten were mostly Daphnia spp. (98\% of zooplankton eaten) along with copepods, Bosminidae, and large-bodied benthic Chydoridae. Chironomidae were the only other major prey eaten by age- 0 lake whitefish ( $8 \%$ ). Medium bodied lake whitefish ate a wider array of prey across the main basin of Lake Huron during the May-September period. The major diet items for medium lake whitefish included D. bugensis (24\%), zooplankton (20\%), Chironomidae (17\%), and Bythotrephes longimanus (12\%). The zooplankton eaten were mainly copepods (59\% of zooplankton eaten) and Daphnia spp. (34\% of zooplankton eaten). Large lake whitefish ate mainly shelled prey including D. bugensis (54\%) and Gastropoda (27\%) (Table 1). Fish accounted for $8 \%$ of the large lake whitefish diets in the main basin. These were mainly nine-spine sticklebacks Pungitius pungitius ( $43 \%$ of all fish eaten) and round gobies Neogobius melanostomus ( $27 \%$ of all fish eaten). Diporeia were $\leq 1 \%$ of the diet for all sizes of lake whitefish.

\section{Discussion}

Benthic macroinvertebrate populations in the main basin of Lake Huron have been little studied when compared to populations in the other Great Lakes. Prior to our survey in 2000, the most recent wide-scale benthic surveys in the main basin occurred in the early 1970s (Schelske and Roth, 1973; Shrivastava, 1974, Great Lakes Research Division [GLRD], University of Michigan, unpublished data). For various reasons, some of which are related to differences in methodology, these earlier surveys differed widely in reported abundances (Nalepa et al., 2007a). When considering methodology, spatial coverage, and level of identification, the GLRD survey in 1972 probably best represents the status of the benthic community in the early 1970s. Our 2000 survey was thus designed so populations in 2000 could realistically be compared to those found in 1972. Collection methods in the two surveys were exactly the same (three replicates per site using the same sampler type and mesh size), many stations were similarly located $(n=25$ with 

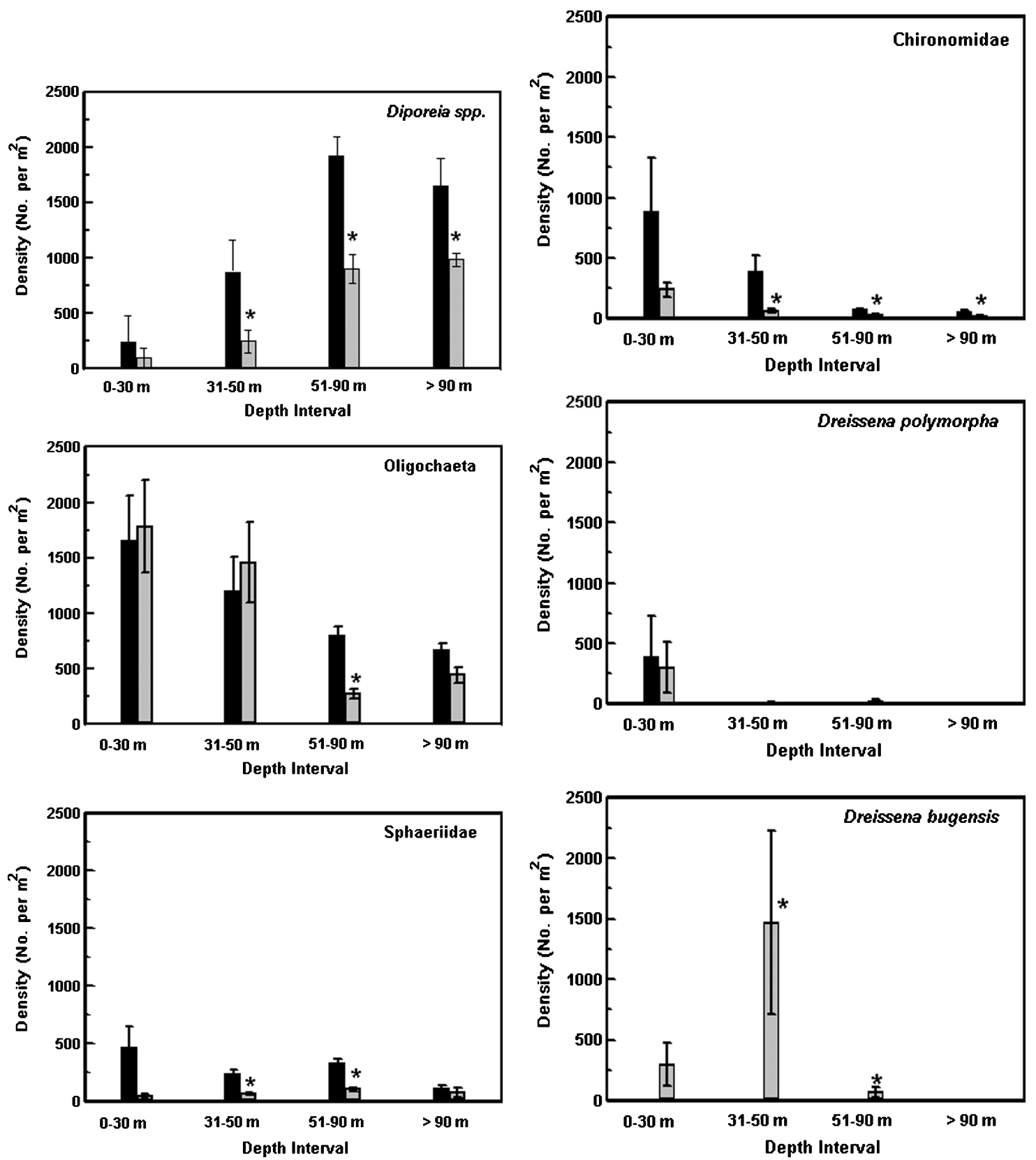

Figure 2. Mean $( \pm \mathrm{SE})$ density (No. per $\left.\mathrm{m}^{2}\right)$ of Diporeia spp., Oligochaeta, Sphaeriidae, Chironomidae, Dreissena polymorpha, and Dreissena bugensis at each of four depth intervals in Lake Huron in 2000 (black) and 2003 (gray). Asterisk (*) indicates there was a significant difference (Mann Whitney U-Test; $\mathrm{P}<0.05$ ) between years.

exact coordinates), and sampling was conducted about the same time of year (August-September). Detailed depth-specific, statistical comparisons between the 1972 and 2000 surveys are given in Nalepa et al. (2007a). In brief, total mean density of the non-dreissenid community (Diporeia,
Oligochaeta, Sphaeriidae, Chironomidae) declined from $8,202 \pm 807 \cdot \mathrm{m}^{-2}$ in 1972 to $2,400 \pm 327 \cdot \mathrm{m}^{-2}$ in 2000 . This is a decline of $70.7 \%$ over the 28 -year period, or $2.5 \%$ per year. Since there were no lake wide surveys conducted between 1972 and 2000, it is difficult to discern exact reasons for lower 
Table 1. Lake whitefish diet in the main basin of Lake Huron during 2002-2004 expressed as percent of total measured wet weight of various prey items for three size groups of lake whitefish: age- 0 , medium ( $\leq 350 \mathrm{~mm}$ TL excluding age- 0 ), and large (>350 mm TL). $\mathrm{N}=$ total number of fish with food in stomachs. $\mathrm{T}=$ trace.

\begin{tabular}{lccc}
\hline & Age-0 & Medium & Large \\
\hline Diporeia spp. & 0 & 1 & $\mathrm{~T}$ \\
Chironomidae & 8 & 17 & 2 \\
Mysis diluviana & 2 & 6 & $\mathrm{~T}$ \\
Ostracoda & 2 & 7 & $\mathrm{~T}$ \\
Sphaeriidae & $\mathrm{T}$ & 4 & $\mathrm{~T}$ \\
Gastropoda & 0 & 1 & 27 \\
Dreissena bugensis & 0 & 24 & 54 \\
Dreissena polymorpha & 0 & $\mathrm{~T}$ & 2 \\
Zooplankton & 87 & 20 & $\mathrm{~T}$ \\
Bythotrephes longimanus & $\mathrm{T}$ & 12 & 2 \\
Fish & 0 & 1 & 8 \\
Other & 1 & 7 & 5 \\
& & & \\
N & 238 & 288 & 364 \\
\hline
\end{tabular}

abundances in 2000, but declines were most likely a result of both phosphorus abatement and the establishment of Dreissena. Phosphorus control measures were initiated in the late $1970 \mathrm{~s}$, and loads declined over $15 \%$ from 5.1 million $\mathrm{kg} /$ year in 1978 to below target levels of 4.3 million $\mathrm{kg} /$ year in 1981 (Beeton et al., 1999). Loads have remained below these levels ever since. Phytoplankton biomass also generally declined (Dobiesz et al., 2005). Lower phosphorus and water column productivity leads to less food material settling to the benthic region and consequently lower benthic abundances. In the time period after phosphorus abatement (but before Dreissena), densities of Diporeia, Oligochaeta, and Sphaeriidae in Lake Michigan declined at a rate of $2.6 \%$ to $8.2 \%$ per year at sites $18-30 \mathrm{~m}$, and $0.7 \%$ to $2.9 \%$ per year at sites $31-50 \mathrm{~m}$. Because of the lack of temporal data, the response of the benthic community to phosphorus abatement in Lake Huron cannot be determined. However, as suggested by Nalepa et al., (2007a), depth specific decline patterns after abatement were probably similar to those in Lake Michigan. This assumption was based on the likelihood that rates of abundance increases prior to abatement were similar in the two lakes. At any rate, Dreissena became established in Lake Huron in the early 1990s, and changes in the benthic community in Saginaw Bay became apparent within just a few years (Nalepa et al., 2003).

While both phosphorus abatement and Dreissena played a role in benthic declines in the main basin of Lake Huron between 1972 and 2000, for various reasons we believe that declines between 2000 and 2003 were a sole result of Dreissena. For one, the total decline in density of the four major non-dreissenid taxonomic groups between 2000 and 2003 was $44.4 \%$, or $14.7 \%$ per year. This was far greater than the $2.5 \%$ per year decline between 1972 and 2000. Further, phosphorus loads have remained generally stable since the early 1980 s, while the dreissenid population expanded greatly between 2000 and 2003 due to increases in D. bugensis. Declines in densities of Diporeia and Sphaeriidae were pronounced over this 3-year period, and other studies in the Great Lakes have shown that these taxa are highly impacted by Dreissena (Dermott and Kerec, 1997; Nalepa et al., 1998; Lauer and McComish, 2001). In a study of benthic community changes between 1980-81 and 2002-2003 in South Bay, located in the northeastern portion of the lake, all major taxa except Oligochaeta declined (McNickle et al., 2006). Oligochaete abundances actually increased, and this increase was attributed to the availability of dreissenid biodeposits as a food source. Similarly, we found that mean densities of oligochaetes at sites $<50 \mathrm{~m}$ were higher in 2003 compared to 2000, although the difference was not significant.

Recent major trends in the benthic community of Lake Huron (i.e., decrease in Diporeia and increase in dreissenids), are reflected in the diet of medium and large lake whitefish. Historically, Diporeia was a major food item of large lake whitefish in Lake Huron, accounting for $82 \%$ of all prey consumed (Ihssen et al., 1981). In 2002-2004, Diporeia was rarely found in the diet. Lake whitefish generally forage at depths $<50 \mathrm{~m}$, and the lakewide density of $D i$ poreia at $0-50 \mathrm{~m}$ in 2003 was $190 \cdot \mathrm{m}^{-2}$ (Nalepa et al., 2007a). Thus, although at least some Diporeia were still present within the preferred foraging depths of lake whitefish, abundances may no longer be high enough to be an energetically profitable food source. On the other hand, the $D$. bugensis population has increased in the lake, and this species has now become the dominant food item of both medium and large lake whitefish. Although molluscs have historically always played some role in the diet of large lake whitefish, the increased importance of shelled prey in Lake Huron was also observed in Lakes 
Michigan and Ontario after dreissenids became established and Diporeia declined (Pothoven et al., 2001, Owens and Dittman, 2003).

The shift in diet from Diporeia to Dreissena has been implicated in the recent decline of lake whitefish condition, growth, and abundance (Pothoven et al., 2001; Owens et al., 2005, Pothoven and Madenjian, 2008). For example, average growth (weight at age) declined $43 \%$ across three management areas in Lake Huron and 25\% across three management areas in Lake Michigan following the dreissenid invasion (Pothoven and Madenjian, 2008). Diporeia have a higher caloric content compared to Dreisenna and other prey items, and were therefore a relatively energy-rich source of food. Based on energy content alone, it has been estimated that the loss of Diporeia would result in a $26-43 \%$ decrease in prey energy available to lake whitefish (McNickle et al., 2006). Further, Diporeia were readily available to fish because of their high abundance and their life-habit excursions into the water column. While dreissenids are also abundant and readily available, fish likely expend additional energy in handling and digestion of the shell, and ensuing gut passage likely occurs at a relatively slow rate. Other prey items found in the diet of medium and large lake whitefish in Lake Huron such as chironomids and zooplankton have relatively high foraging costs. For instance, chironomid densities were far lower relative to Diporeia even prior to Dreissena, and zooplankton are small relative to benthic prey, making them less cost-efficient as an energy source for larger fish. Lake whitefish stocks that ate large amounts of zooplankton grew slower than fish that ate larger prey (Ihssen et al., 1981). Another prey item, Mysis diluviana, has an energy content similar to Diporeia, but our data indicates that lake whitefish in Lake Huron do not seem to be feeding on Mysis to any extent. In contrast, Mysis became more prominent in the diet of lake whitefish after Diporeia declined in Lakes Michigan and Ontario (Pothoven et al., 2001; Owens and Dittman, 2003). Densities of Mysis in northern Lake Huron $(30-60 \mathrm{~m})$ averaged $16 \cdot \mathrm{m}^{-2}$ during 2002-2004 compared to $67 \cdot \mathrm{m}^{-2}$ at over the same depth range in southern Lake Michigan in 2002 (S. Pothoven, Great Lakes Environmental Research Laboratory, NOAA Ann Arbor, MI, unpublished data), so Mysis may not be as readily available in Lake Huron compared to Lake Michigan.

Based on trends in Lake Ontario, where $D . b u$ gensis became established seven years before it became established in Lake Huron (Nalepa et al.,
2001), we expect that the D. bugensis population in Lake Huron will continue to expand, particularly at deeper depths and, as a result, the Diporeia population will continue to decline. Changes in abundances of other benthic groups can also be expected. Lake whitefish have adaptive, flexible feeding patterns, so it is difficult to predict ultimate consequences to populations. However, as noted, initial impacts have been negative (Mohr and Nalepa, 2005). The shift from Diporeia to Dreissena will likely have a disproportionate impact on mediumsized fish. In Lake Huron, medium-sized fish appeared to be more reliant on non-mollusc macroinvertebrates than large-sized fish, and obtained eight times less energy than large fish for the average sized dreissenid eaten (Pothoven and Nalepa, 2006). This finding alone will have long-term impacts on prereproductive growth rates and the age at which lake whitefish reach maturity. While field studies can define changes in diet, laboratory studies are needed to better define feeding costs relative to benefits of the various prey items. Such a combination of studies will better define how lake whitefish populations will respond to benthic changes over the long term.

\section{Conclusions}

Abundances of most major, non-dreissenid benthic groups in the main basin of Lake Huron declined between 2000 and 2003. Significant declines were evident in Diporeia, Sphaeriidae, and Chironomidae, while consistent trends in Oligochaeta were not apparent. Most likely these trends were related to the great increase in abundances of $D$. bugensis over the same period. These changes, particularly the decline of Diporeia, will likely have broad implications for the commercially-important lake whitefish, which relied on Diporeia as a major source of food. The diet of lake whitefish in 2002-2004 varied by fish size, but Diporeia was rarely found in the stomachs of medium and large fish while D. bugensis was dominant. D. bugensis has a lower energy content compared to Diporeia and the replacement of the latter by the former in diets suggests a major shift in lake whitefish bioenergetics.

\section{Acknowledgements}

We thank the crews of the R/V Laurentian and R/ V Lake Guardian for their help and assistance during field operations; the Great Lakes National Program Office, Environmental Protection Agency for 
use of the Lake Guardian and partial funding; the Michigan Great Lakes Protection Fund for partial funding; Michael Winnell for providing the unpublished 1972 data; Steve Lozano and Andrew Foley, III for assistance during field collections; and the many students that helped sort and process the samples. This is Great Lakes Environmental Research Laboratory Publication No. 1443.

\section{References}

Bially, A., MacIsaac, H.J., 2000. Fouling mussels (Dreissena spp.) colonize soft sediments in Lake Erie and facilitate benthic invertebrates. Freshwater Biol. 43, 85-97.

Beeton, A.M., Sellinger, C.E., Reid, D.F., 1999. An introduction to the Great Lakes ecosystem. In: W.W. Taylor and C.P. Ferreri (Eds.), Great Lakes Fisheries Policy and Management: a Binational Perpsective, pp. 3-54. Michigan State University Press, East Lansing, MI.

Christie, W.J., Scott, K.A., Sly, P.G., Strus, R.H., 1987. Recent changes in the aquatic food web of eastern Lake Ontario. Can. J. Fish. Aquat. Sci. 44 (Suppl. 2), 37-42.

Dermott, R., Kerec, D., 1997. Changes in deepwater benthos of eastern Lake Erie since the invasion of Dreissena: 19731993. Can. J. Fish. Aquat. Sci. 54, 922-930.

Dobiesz, N.E., McLeish, D.A., Eshenroder, R.L., Bence, J.R., Mohr, L.C., Henderson, B.A., Ebener, M.P, Nalepa, T.F., Woldt, A.P, Johnson, J.E., Argyle, R.L., Makarewicz, J.C., 2005. Ecology of the Lake Huron Fish Community 19701999. Can. J. Fish. Aquat. Sci. 62, 1432-1451.

Gonzalez, M.J., Downing, A., 1999. Mechanisms underlying amphipod responses to zebra mussel (Dreissena polymorpha) invasion and implications for fish-amphipod interactions. Can. J. Fish. Aquat. Sci. 56, 679-685.

Haynes, J.M., Tisch, N.A., Mayer, C.M., Rhyne, R.S., 2005. Benthic macroinvertebrate communities in southwestern Lake Ontario following invasion of Dreissena and Echinogammarus: 1993 to 2000. J. N. Amer. Benth. Soc. 24, 148-167.

Howell, E.T., Marvin, C.H., Bilyea, R.W., Kauss, P.B., Somers, K., 1996. Changes in environmental conditions during Dreissena colonization of a monitoring station in eastern Lake Erie. J. Great Lakes Res. 22, 744-756.

Ihssen, P.E., Evans, D.O., Christie, W.J., Reckahn, J.A., DesJardine, R.L., 1981. Life history, morphology, and electrophoretic characteristics of five allopatric stocks of lake whitefish (Coregonus clupeaformis) in the Great Lakes region. Can. J. Fish. Aquat. Sci. 38, 1790-1807.

Lauer, T.E., McComish, T.S., 2001. Impact of zebra mussels (Dreissena polymorpha) on fingernail clams (Sphaeriidae) in extreme southern Lake Michigan. J. Great Lakes Res. 27, 230-238.

McNickle, G.G., Rennie, M.D., Sprules, W.G. 2006. Changes in benthic invertebrate communities of South Bay, Lake Huron following invasion by zebra mussels (Dreissena polymorpha), and potential effects on Lake Whitefish (Coregonus clupeaformis) diet and growth. J. Great Lakes Res. 32, 180193.
Mohr, L.C., Ebener, M.P., 2005. Status of lake whitefish (Coregonus clupeaformis) in Lake Huron. p. 87-104. In: L. C. Mohr and T. F. Nalepa (Eds.). Proceedings of a workshop on the dynamics of lake whitefish (Coregonus clupeaformis) and the amphipod Diporeia spp. in the Great Lakes. Great Lakes Fisheries Commission Technical Report 66, Ann Arbor, Michigan.

Mohr, L.C., Nalepa, T.F., 2005. Proceedings of a Workshop on the Dynamics of Lake Whitefish (Coregonus clupeaformis) and the Amphipod Diporeia spp. in the Great Lakes, 2002 February. Technical Report 66. Great Lakes Fishery Commission, Ann Arbor, MI.

Nalepa, T.F., Hartson, D.J., Fanslow, D.L., Lang, G.A., Lozano, S.J. 1998. Declines in benthic macroinvertebrate populations in southern Lake Michigan, 1980-1993. Can. J. Fish. Aquat. Sci. 55, 2402-2413.

Nalepa, T.F., Schloesser, D.W., Pothoven, S.A., Hondorp, D.W., Fanlsow, D.L., Tuchman, M.L., Fleischer, G.W., 2001. First finding of the amphipod Echinogammarus ischnus and the mussel Dreissena bugensis in Lake Michigan. J. Great Lakes Res. 27, 384-391.

Nalepa, T.F., Fanslow, D.L., Lansing, M.B., Lang, M.A., 2003. Trends in the benthic macroinvertebrate community of Saginaw Bay, Lake Huron, 1987 to 1996: responses to phosphorus abatement and the zebra mussel, Dreissena polymorpha. J. Great Lakes Res. 29, 14-33.

Nalepa, T.F., Rockwell, D.C., Schloesser, D.W., 2006. Disappearance of the amphipod Diporeia spp. in the Great Lakes: Workshop summary, discussion, and recommendations. NOAA Technical Memorandum GLERL-136. NOAA, Great Lakes Environmental Research Laboratory, Ann Arbor, MI.

Nalepa, T.F., Fanslow, D.L., Pothoven, S.A., Foley, A.J., III, and Lang, G.A., 2007a. Long-term trends in benthic macroinvertebrate populations in Lake Huron over the past four decades. J. Great Lakes Res. 33, 421-436.

Nalepa, T.F., Fanslow, D.L., Pothoven, S.A., Foley, A.J., III, Lang, G.A., Mozley, S.C., and Winnell, M.W., 2007b. Abundance and distribution of benthic macroinvertebrate populations in Lake Huron, Georgian Bay and North Channel in 1972 and 2000-2003. NOAA Technical Memorandum GLERL-140. NOAA, Great Lakes Environmental Research Laboratory, Ann Arbor, MI.

Owens, R.W., Dittman, D.E., 2003. Shifts in the diets of slimy sculpin (Cottus cognatus) and lake whitefish (Coregonus clupeaformis) in Lake Ontario following the collapse of the burrowing amphipod Diporeia. Aquat. Ecosystem Health and Management 6, 311-323.

Owens, R.W., O'Gorman, R., Eckert, T.H., Landry, B.F., Dittman, D.E., 2005. Recovery and decline of lake whitefish in U. S. waters of eastern Lake Ontario, 1980-2001. p. 141-155. In: L. C. Mohr and T. F. Nalepa (Eds.) Proceedings of a workshop on the dynamics of lake whitefish (Coregonus clupeaformis) and the amphipod Diporeia spp. in the Great Lakes. Great Lakes Fisheries Commission Technical Report 66, Ann Arbor, Michigan.

Pothoven, S.A., Nalepa, T.F., Schneeberger, P.J., Brandt, S.B., 2001. Changes in diet and body condition of lake whitefish in southern Lake Michigan associated with changes in benthos. North Am. J. Fish. Manage. 21, 876-883. 
Pothoven, S.A., Nalepa, T.F., 2006. Feeding ecology of lake whitefish in Lake Huron. J. Great Lakes Res. 32, 489-501.

Pothoven, S.A., Madenjian, C.P., Changes in consumption of alewives and lake whitefish after dreissenid invasions in Lakes Michigan and Huron. North Amer. J. Fish. Manage. 28, 308-320.
Schelske, C.L., Roth, J.C., 1973. Limnological survey of Lakes Michigan, Superior, Huron, and Erie. Great Lakes Research Division Publ. No. 17, University of Michigan, Ann Arbor, MI.

Shrivastava, H., 1974. Macrobenthos of Lake Huron. Fish. Res. Bd. Canada, Tech. Rep. 449. 